\title{
Evaluasi Koleksi Perpustakaan Fakultas Ilmu Budaya Universitas Lancang Kuning berdasarkan RPS
}

\section{Evaluation of The Library Collection of The Faculty of Cultural Sciences at The University of Lancang Kuning Based on RPS}

\author{
Melgia Safitri*, Nining Sudiar**, Triono Dul Hakim*** \\ Library Science, Faculty of Cultural Science, \\ Lancang Kuning University, Indonesia \\ melgigia1@gmail.com
}
Received : $14^{\text {th }}$ October 2021; Revised : $11^{\text {th }}$ November 2021; Accepted : $13^{\text {th }}$ November 2021

Available Online $: 5^{\text {th }}$ December 2021; Published Regularly : $5^{\text {th }}$ December 2021

\begin{abstract}
This study aims to identify the availability level of the library collection of the Faculty of Cultural Sciences, the University of Lancang Kuning based on the RPS. This research method is descriptive quantitative. The sample in this study is all available RPS in the curriculum totaling 193 RPS, data as per April 28, 2021. The results of this study indicate the availability of a collection of compulsory subjects from the four majors in the Faculty of Cultural Sciences from the total required collection is quite a small portion, namely $18 \%$ or 146 titles of collections, are available in the Library of the Faculty of Cultural Sciences. But most of them, $82 \%$ or 656 collection titles, are not available in the Library of the Faculty of Humanities. In addition, the availability of a collection of elective courses from the four majors in the Faculty of Cultural Sciences of the total collection needed is almost half, namely $24 \%$ or 13 collection titles available in the Library of the Faculty of Cultural Sciences. Besides that, $76 \%$ or 42 collections, are not available in the Library of the Faculty of Cultural Sciences.
\end{abstract}

Keywords: evaluation; collection availability; semester lesson plan

\begin{abstract}
Abstrak
Penelitian ini bertujuan untuk mengidentifikasi tingkat ketersediaan koleksi Perpustakaan Fakultas Ilmu Budaya, Universitas Lancang Kuning berdasarkan RPS. Metode penelitian ini adalah deskriptif kuantitatif. Sampel pada penelitian ini adalah seluruh RPS yang tersedia pada kurikulum berjumlah 193 RPS, data sampel diambil pada tanggal 28 April 2021. Hasil penelitian ini menunjukkan bahwa ketersediaan koleksi mata kuliah wajib dari keempat jurusan yang ada di Fakultas Ilmu Budaya dari total koleksi yang dibutuhkan, sebagian kecil, yaitu $18 \%$ atau 146 judul koleksi, tersedia di Perpustakaan Fakultas Ilmu Budaya. Sebagian besar, yaitu $82 \%$ atau 656 judul koleksi, tidak tersedia di Perpustakaan Fakultas Ilmu Budaya. Kemudian ketersediaan koleksi mata kuliah pilihan dari keempat jurusan yang ada di Fakultas Ilmu Budaya dari total koleksi yang dibutuhkan hampir setengah, yaitu 24\% atau 13 judul koleksi, tersedia di Perpustakaan Fakultas Ilmu Budaya. Sedangkan, lebih dari setengah, yaitu $76 \%$ atau 42 judul koleksi, tidak tersedia di Perpustakaan Fakultas Ilmu Budaya.
\end{abstract}

Kata kunci: Evaluasi; ketersediaan koleksi; rencana pembelajaran semester

\section{Pendahuluan}

Perpustakaan perguruan tinggi didirikan guna memenuhi kebutuhan informasi bagi para akademisi (dosen maupun mahasiswa) dan masyarakat kampus (tenaga pendidikan). Salah 
satunya dengan menyediakan bahan pustaka (koleksi) sebagai referensi untuk memperlancar proses pembelajaran yang diselenggarakan oleh perguruan tinggi (Junaeti, 2019).

Menurut Sutarno (2006) koleksi perpustakaan universitas harus sesuai dengan program atau materi kuliah dan disiplin ilmu serta materi pendukung bagi jurusan, program studi, fakultas, universitas yang ada. Koleksi yang disediakan hendaknya merupakan koleksi yang mendukung tercapainya tujuan pembelajaran serta materi kuliah sesuai program studi. Oleh karena itu, perlu dilakukan evaluasi koleksi agar koleksi tersebut dapat sesuai dengan kurikulum yang sedang diterapkan (Romadhoni, 2016).

Evaluasi koleksi adalah salah satu cara untuk mengetahui sejauh mana tingkat ketersediaan koleksi dan bagaimana keterpakaian koleksi tersebut oleh pengguna. Evaluasi ini sangat penting dilakukan guna mengetahui keberadaan koleksi dan relevansinya dengan kurikulum dalam perguruan tinggi.

Dalam Peraturan Menteri Riset, Teknologi, dan Pendidikan Tinggi Republik Indonesia Nomor 44 Tahun 2015 tentang Standar Nasional Pendidikan Tinggi (2015), kurikulum diartikan sebagai, seperangkat rencana maupun pengaturan mengenai capaian pembelajaran lulusan, bahan kajian, proses, dan penilaian yang akan digunakan sebagai pedoman penyelenggaraan program studi. Selanjutnya disebutkan bahwa, kurikulum pendidikan perguruan tinggi dikembangkan menjadi Rencana Pembelajaran Semester (RPS).

RPS merupakan proses atau cara pembelajaran dalam setiap mata kuliah yang dibuat serta dikembangkan oleh dosen-dosen yang bersangkutan secara mandiri atau bersama dalam keahlian suatu bidang ilmu pengetahuan dan/atau teknologi/seni dalam program studi (Peraturan Menteri Riset, Teknologi, dan Pendidikan Tinggi Republik Indonesia Nomor 44 Tahun 2015 tentang Standar Nasional Pendidikan Tinggi, 2015 pasal 12 ayat 2). RPS tersebut dijadikan pedoman dalam proses pembelajaran atau kegiatan perkuliahan dalam satu semester oleh dosen dan mahasiswa.

Fakultas Ilmu Budaya (FIB) Universitas Lancang Kuning merupakan satu-satunya Fakultas Ilmu Budaya yang ada di Riau. Fakultas Ilmu Budaya memiliki empat jurusan yaitu Sastra Melayu, Sastra Indonesia, Sastra Inggris, dan Ilmu Perpustakaan. Fakultas Ilmu Budaya memiliki perpustakaan yang menyediakan koleksi penunjang pembelajaran bagi mahasiswa.

Menurut pustakawan yang bertugas di Perpustakaan FIB, pengadaan koleksi Perpustakaan FIB dilakukan berdasarkan RPS dan permintaan dosen. Akan tetapi, tidak semua referensi yang terdapat di RPS disediakan oleh perpustakaan. Hal ini dibuktikan oleh penuturan dari beberapa pengunjung, bahwa ketika mencari buku referensi mata kuliah tidak semua mereka dapatkan di Perpustakaan FIB. Terkait hal tersebut penulis tertarik meneliti tentang "Evaluasi Koleksi Perpustakaan Fakultas Ilmu Budaya Universitas Lancang Kuning berdasarkan RPS".

\section{Metode Penelitian}

Jenis penelitian ini adalah deskriptif dengan pendekatan kuantitatif. Dalam mengumpulkan data untuk kepentingan penelitian ini, peneliti menggunakan metode pengumpulan data yaitu observasi. Pengambilan data dilakukan pada tanggal 28 April-10 Mei 2021. Analisis data dilakukan dengan pengecekan koleksi bahan ajar di OPAC perpustakaan guna mengetahui ketersediaan koleksi. Kemudian rumus yang digunakan dalam menghitung persentase yaitu, 


$$
P=\frac{F}{N} \times 100 \%
$$

Keterangan:

$$
\begin{array}{ll}
\mathrm{P} & \text { : Persentase } \\
\mathrm{F} & \text { : Frekuensi ketersediaan koleksi } \\
\mathrm{N} & \text { : Jumlah seluruh frekuensi } \\
100 \% & \text { : Bilangan konstanta }
\end{array}
$$

Setelah dilakukan perhitungan, maka hasil persentase tersebut ditafsirkan dengan menggunakan kriteria sebagai berikut,

$$
\begin{array}{ll}
81-100 \% & : \text { Sebagian besar } \\
61-80 \% & : \text { Lebih dari setengah } \\
41-60 \% & : \text { Setengah } \\
21-40 \% & : \text { Hampir setengah } \\
0-20 \% & : \text { Sebagian kecil }
\end{array}
$$

\begin{tabular}{|c|c|c|c|c|}
\hline No. & Mata Kuliah & $\begin{array}{l}\text { Jumlah } \\
\text { Referensi }\end{array}$ & $\begin{array}{l}\text { Jumlah Koleksi } \\
\text { yang Tersedia }\end{array}$ & $\begin{array}{c}\text { Jumlah Koleksi } \\
\text { yang Tidak } \\
\text { Tersedia }\end{array}$ \\
\hline 1. & Pendidikan Pancasila & 8 & 2 & 6 \\
\hline 2. & Bahasa Inggris & 8 & 2 & 6 \\
\hline 3. & Dasar-Dasar Ilmu Budaya & 3 & 1 & 2 \\
\hline 4. & $\begin{array}{l}\text { Sejarah Kebudayaan } \\
\text { Indonesia }\end{array}$ & 8 & 1 & 7 \\
\hline 5. & Seni I & 7 & - & 7 \\
\hline 6. & Pengantar Linguistik Umum & 5 & 1 & 4 \\
\hline 7. & Pengantar Ilmu Sastra & 8 & 2 & 6 \\
\hline 8. & Pengantar Filologi & 6 & 4 & 2 \\
\hline 9. & Pengelolaan Kelas & 4 & - & 4 \\
\hline 10. & $\begin{array}{l}\text { Pendidikan } \\
\text { Kewarganegaraan }\end{array}$ & 6 & 1 & 5 \\
\hline 11. & Pendidikan Agama & 3 & - & 3 \\
\hline 12. & Bahasa Indonesia & 3 & - & 3 \\
\hline 13. & Tradisi Melayu & 11 & 4 & 7 \\
\hline 14. & Bahasa Inggris II & 5 & 1 & 4 \\
\hline 15. & Dasar-Dasar Filsafat & 4 & 1 & 3 \\
\hline 16. & Pengantar Komputer & 7 & - & 7 \\
\hline 17. & Seni II & 3 & - & 3 \\
\hline 18. & Fonologi Bahasa Melayu & 5 & 2 & 3 \\
\hline 19. & Teori Sastra I & 5 & 1 & 4 \\
\hline
\end{tabular}

\section{Hasil dan Pembahasan}

\section{Ketersediaan Koleksi Bahan Ajar Mata Kuliah Wajib}

Mata kuliah wajib adalah mata kuliah yang harus diambil oleh mahasiswa, di mana mata kuliah tersebut menjadi dasar dari sebuah program studi. Setiap program studi dapat memiliki mata kuliah wajib yang berbeda-beda. Berikut ini merupakan ketersediaan koleksi bahan ajar mata kuliah wajib program studi Sastra Melayu, Sastra Indonesia, Sastra Inggris, dan Ilmu Perpustakaan.

\section{Tabel 1.}

Ketersediaan koleksi bahan ajar mata kuliah wajib Sastra Melayu 
Palimpsest: Journal of Information and Library Science Vol 12, Issue 2, (2021) page 58-68

\begin{tabular}{|c|c|c|c|c|}
\hline No. & Mata Kuliah & $\begin{array}{c}\text { Jumlah } \\
\text { Referensi }\end{array}$ & $\begin{array}{l}\text { Jumlah Koleksi } \\
\text { yang Tersedia }\end{array}$ & $\begin{array}{c}\text { Jumlah Koleksi } \\
\text { yang Tidak } \\
\text { Tersedia }\end{array}$ \\
\hline 20. & Sejarah Melayu & 6 & 1 & 5 \\
\hline 21. & Kewirausahaan & 2 & - & 2 \\
\hline 22. & $\begin{array}{l}\text { Kurikulum dan } \\
\text { Pembelajaran }\end{array}$ & 11 & - & 11 \\
\hline 23. & Bahasa Melayu I & 2 & 1 & 1 \\
\hline 24. & Bahasa Arab I & 5 & - & 5 \\
\hline 25. & Sintaksis Bahasa Melayu & 3 & - & 3 \\
\hline 26. & Morfologi Bahasa Melayu & 8 & 1 & 7 \\
\hline 27. & Folklor Bahasa Melayu & 3 & - & 3 \\
\hline 28. & Kodikologi & 3 & 2 & 1 \\
\hline 29. & Teori Sastra II & 5 & 3 & 2 \\
\hline 30. & Cipta Sastra & 2 & 1 & 1 \\
\hline 31. & Bahasa Melayu II & 2 & 1 & 1 \\
\hline 32. & Bahasa Arab II & 2 & - & 2 \\
\hline 33. & Semantik Bahasa Melayu & 3 & 1 & 2 \\
\hline 34. & Pemikiran Melayu I & 2 & 1 & 1 \\
\hline 35. & Orientalisme & 5 & - & 5 \\
\hline 36. & Evaluasi dan Pembelajaran & 5 & - & 5 \\
\hline 37. & Kritik Sastra Melayu & 4 & 1 & 3 \\
\hline 38. & Aksara Arab Melayu & 2 & 2 & - \\
\hline 39. & Metode Penelitian I & 7 & 4 & 3 \\
\hline 40. & Telaah Pranata Melayu & 5 & 2 & 3 \\
\hline 41. & Pemikiran Melayu II & 4 & 1 & 3 \\
\hline 42. & Kritik Teks Naskah & 4 & 3 & 1 \\
\hline 43. & Kepariwisataan & 2 & - & 2 \\
\hline 44. & Pragmatik Bahasa Melayu & 5 & - & 5 \\
\hline 45. & Applicative English & 6 & 1 & 5 \\
\hline 46. & Sastra Banding & 7 & 2 & 5 \\
\hline 47. & Diplomasi Budaya & 2 & - & 2 \\
\hline 48. & Metode Penelitian II & 3 & - & 3 \\
\hline 49. & Penulisan Karya Ilmiah & 5 & - & 5 \\
\hline 50. & Sinematografi & 4 & - & 4 \\
\hline 51. & Penyiaran & 10 & - & 10 \\
\hline 52. & Pengantar Jurnalistik & 8 & 1 & 7 \\
\hline 53. & Dialektologi & 4 & 2 & 2 \\
\hline 54. & PKL & 1 & 1 & - \\
\hline 55. & Skripsi & 1 & 1 & - \\
\hline \multicolumn{2}{|r|}{ Jumlah } & 262 & 56 & 206 \\
\hline \multicolumn{2}{|r|}{ Persentase } & & $21 \%$ & $79 \%$ \\
\hline
\end{tabular}

Sumber: Data diolah April 2021

Menurut tabel di atas dapat dilihat bahwa ketersediaan koleksi perpustakaan berdasarkan RPS untuk mata kuliah wajib jurusan Sastra Melayu yaitu terdapat 56 judul koleksi rujukan yang tersedia dari 262 judul yang dibutuhkan dengan persentase $21 \%$ atau hampir setengahnya koleksi yang tersedia dan koleksi yang tidak tersedia sebanyak 206 judul dengan persentase $79 \%$ atau lebih dari setengahnya.

Berdasarkan hasil penelitian, terdapat 2 RPS yang tidak tersedia, yaitu mata kuliah Telaah Naskah Melayu dan Digitalisasi Naskah. Selanjutnya untuk mata kuliah wajib jurusan 
Sastra Melayu yang paling banyak memiliki koleksi bahan ajar akan tetapi sedikit ketersediaannya adalah mata kuliah kurikulum dan pembelajaran.

Tabel 2.

Ketersediaan koleksi bahan ajar mata kuliah wajib Sastra Indonesia

\begin{tabular}{|c|c|c|c|c|}
\hline No. & Mata Kuliah & $\begin{array}{c}\text { Jumlah } \\
\text { Referensi }\end{array}$ & $\begin{array}{l}\text { Jumlah Koleksi } \\
\text { yang Tersedia }\end{array}$ & $\begin{array}{c}\text { Jumlah Koleksi yang } \\
\text { Tidak Tersedia }\end{array}$ \\
\hline 1. & Dasar-Dasar Filsafat & 5 & - & 5 \\
\hline 2. & Pengantar Linguistik Umum & 4 & 1 & 3 \\
\hline 3. & Pengantar Ilmu Sastra & 5 & - & 5 \\
\hline 4. & Bahasa Indonesia & 3 & - & 3 \\
\hline 5. & Budaya Melayu & 4 & - & 4 \\
\hline 6. & Pengantar Komputer & 4 & - & 4 \\
\hline 7. & Pengantar Jurnalistik & 7 & 2 & 5 \\
\hline 8. & Fonologi Bahasa Indonesia & 4 & 2 & 2 \\
\hline 9. & Stilistika & 3 & 1 & 2 \\
\hline 10. & Estetika & 5 & - & 5 \\
\hline 11. & Teori Sastra I & 4 & - & 4 \\
\hline 12. & Telaah Puisi & 3 & - & 3 \\
\hline 13. & Kritik Sastra Indonesia & 4 & - & 4 \\
\hline 14. & Teori Sastra II & 4 & - & 4 \\
\hline 15. & Telaah Drama & 6 & - & 6 \\
\hline 16. & $\begin{array}{l}\text { Linguistik Historis } \\
\text { Komparatif }\end{array}$ & 5 & - & 5 \\
\hline 17. & $\begin{array}{l}\text { Metodologi Penelitian } \\
\text { Sastra, Filologi, dan Budaya }\end{array}$ & 3 & 2 & 1 \\
\hline 18. & Sosiologi Sastra & 10 & 4 & 6 \\
\hline 19. & Orientalisme & 12 & 1 & 11 \\
\hline 20. & $\begin{array}{l}\text { Pragmatik dan Analisis } \\
\text { Wacana }\end{array}$ & 5 & - & 5 \\
\hline 21. & Metode Penelitian Linguistik & 7 & 5 & 2 \\
\hline 22. & Psikologi Sastra & 4 & 2 & 2 \\
\hline 23. & Dialektologi & 4 & 2 & 2 \\
\hline & Jumlah & 115 & 22 & 93 \\
\hline & Persentase & & $19 \%$ & $81 \%$ \\
\hline
\end{tabular}

Sumber: Data diolah April 2021

Menurut tabel di atas dapat dilihat untuk mata kuliah wajib jurusan Sastra Indonesia ketersediaan koleksi perpustakaan berdasarkan RPS yang tersedia sebanyak 22 judul dengan persentase $19 \%$ atau sebagian kecil dari 115 judul yang dibutuhkan dan koleksi yang tidak tersedia sebanyak 93 judul atau sebagian besar yaitu $81 \%$ dari koleksi yang dibutuhkan.

Berdasarkan hasil penelitian, terdapat 38 RPS yang tidak tersedia yaitu mata kuliah Pancasila, Sejarah Kebudayaan Indonesia, Dasar-Dasar Ilmu Budaya, Bahasa Inggris, Sejarah Kesusastraan Indonesia, Bahasa Melayu, Pendidikan Agama, Pengantar Filologi, Folklor Indonesia, Bahasa Inggris Sastra, Sastra Klasik, Pendidikan Kewarganegaraan, Kurikulum dan Pembelajaran, Morfologi Bahasa Indonesia, Sastra Lisan, Teori Filologi, Telaah Naskah, Semiotik I, Pengelolaan Kelas, Telaah Prosa, Semantik Bahasa Indonesia, Semiotik II, Aliran Sastra, Praktik Sastra dan Penulisan Kreatif, Evaluasi Pembelajaran, Apresiasi Film dan Sinetron, Kehumasan, Sintaksis Bahasa Indonesia, Hermeneutika, Tata Bahasa Generatif, Sosiolinguistik, Kodikologi, Sastra Banding, Sastra Feminisme, Sinematografi, Seminar 
Proposal, Praktik Kerja Lapangan, serta Skripsi. Selanjutnya untuk mata kuliah wajib jurusan Sastra Indonesia yang paling banyak memiliki koleksi bahan ajar akan tetapi sedikit ketersediaannya adalah mata kuliah Orientalisme.

Tabel 3.

Ketersediaan koleksi bahan ajar mata kuliah wajib Sastra Inggris

\begin{tabular}{|c|c|c|c|c|}
\hline No. & Mata Kuliah & $\begin{array}{c}\text { Jumlah } \\
\text { Referensi }\end{array}$ & $\begin{array}{c}\text { Jumlah Koleksi } \\
\text { yang Tersedia }\end{array}$ & $\begin{array}{c}\text { Jumlah Koleksi yang } \\
\text { Tidak Tersedia }\end{array}$ \\
\hline 1. & Pendidikan Pancasila & 8 & 2 & 6 \\
\hline 2. & Basic Grammar & 3 & 1 & 2 \\
\hline 3. & Basic Reading & 1 & - & 1 \\
\hline 4. & $\begin{array}{l}\text { Intensive Listening \& } \\
\text { Speaking }\end{array}$ & 4 & - & 4 \\
\hline 5. & Dasar-Dasar Filsafat & 4 & 1 & 3 \\
\hline 6. & Dasar-Dasar Ilmu Budaya & 3 & 1 & 2 \\
\hline 7. & $\begin{array}{l}\text { Sejarah Kebudayaan } \\
\text { Indonesia }\end{array}$ & 8 & 1 & 7 \\
\hline 8. & Pengantar Komputer & 7 & - & 7 \\
\hline 9. & Introduction to Linguistics & 5 & - & 5 \\
\hline 10. & Pendidikan Agama & 3 & - & 3 \\
\hline 11. & Budaya Melayu & 1 & - & 1 \\
\hline 12. & Intermediate Grammar & 5 & 1 & 4 \\
\hline 13. & Reading For Various Texts & 5 & - & 5 \\
\hline 14. & $\begin{array}{l}\text { Contextual Listening \& } \\
\text { Speaking }\end{array}$ & 2 & - & 2 \\
\hline 15. & Paragraph Writing & 7 & - & 7 \\
\hline 16. & Bahasa Indonesia & 4 & - & 4 \\
\hline 17. & Phonology & 5 & - & 5 \\
\hline 18. & Introduction to Literature & 1 & 1 & - \\
\hline 19. & Morphology & 6 & - & 6 \\
\hline 20. & $\begin{array}{l}\text { Pendidikan } \\
\text { Kewarganegaraan }\end{array}$ & 6 & 1 & 5 \\
\hline 21. & $\begin{array}{l}\text { Upper Intermediate } \\
\text { Grammar }\end{array}$ & 3 & - & 3 \\
\hline 22. & $\begin{array}{l}\text { Comprehensive Listening \& } \\
\text { Speaking }\end{array}$ & 4 & - & 4 \\
\hline 23. & $\begin{array}{l}\text { English Indonesian } \\
\text { Translation }\end{array}$ & 7 & - & 7 \\
\hline 24. & Literary Theory & 2 & - & 2 \\
\hline 25. & Semantics & 6 & - & 6 \\
\hline 26. & British Culture & 4 & - & 4 \\
\hline 27. & Sociolinguis-tics & 3 & - & 3 \\
\hline 28. & Method of Teaching English & 5 & 1 & 4 \\
\hline 29. & Survey of English Literature & 2 & - & 2 \\
\hline 30. & Advanced Grammar & 2 & - & 2 \\
\hline 31. & $\begin{array}{l}\text { Listening \& Speaking for } \\
\text { Academic Purpose }\end{array}$ & 4 & - & 4 \\
\hline 32. & Eassy Writing & 4 & 1 & 3 \\
\hline 33. & $\begin{array}{l}\text { Indonesia English } \\
\text { Translation }\end{array}$ & 6 & - & 6 \\
\hline 34. & Poetry Analysis 1 & 6 & - & 6 \\
\hline 35. & Drama Analysis 1 & 2 & - & 2 \\
\hline
\end{tabular}


Palimpsest: Journal of Information and Library Science Vol 12, Issue 2, (2021) page 61-68

\begin{tabular}{|c|c|c|c|c|}
\hline No. & Mata Kuliah & $\begin{array}{c}\text { Jumlah } \\
\text { Referensi }\end{array}$ & $\begin{array}{c}\text { Jumlah Koleksi } \\
\text { yang Tersedia }\end{array}$ & $\begin{array}{c}\text { Jumlah Koleksi yang } \\
\text { Tidak Tersedia }\end{array}$ \\
\hline 36. & Prose Analysis 1 & 4 & - & 4 \\
\hline 37. & Pengantar Jurnalistik & 6 & 1 & 5 \\
\hline 38. & American Culture & 4 & - & 4 \\
\hline 39. & $\begin{array}{l}\text { Learning and Teaching } \\
\text { studies }\end{array}$ & 6 & 1 & 5 \\
\hline 40. & Syntax & 6 & - & 6 \\
\hline 41. & Academic Writing & 4 & - & 4 \\
\hline 42. & Practicum of Translation & 5 & - & 5 \\
\hline 43. & Drama Analysis II & 3 & 2 & 1 \\
\hline 44. & Prose Analysis II & 4 & - & 4 \\
\hline 45. & Cultural Studies & 2 & - & 2 \\
\hline 46. & Contrasive Linguistics & 6 & - & 6 \\
\hline 47. & $\begin{array}{l}\text { Method of Research in Ling. } \\
\text { \& Literature } 1\end{array}$ & 5 & 3 & 2 \\
\hline 48. & English for Tourism Industry & 3 & 1 & 2 \\
\hline 49. & Enterpreneur-ship & 5 & - & 5 \\
\hline 50. & Public Relations & 4 & - & 4 \\
\hline 51. & Interpreting & 4 & - & 4 \\
\hline 52. & Comparative Literature & 7 & - & 7 \\
\hline 53. & Literary Criticism & 9 & - & 9 \\
\hline 54. & Pragmatics & 4 & - & 4 \\
\hline 55. & Integrated English & 6 & - & 6 \\
\hline 56. & Discourse Analysis & 6 & - & 6 \\
\hline 57. & English For Business & 6 & - & 6 \\
\hline 58. & Film Analysis & 1 & - & 1 \\
\hline 59. & $\begin{array}{l}\text { Method of Research in Ling. } \\
\& \text { Literature } 2\end{array}$ & 4 & 1 & 3 \\
\hline 60. & Curriculum Studies & 7 & - & 7 \\
\hline 61. & Popular Culture & 9 & - & 9 \\
\hline 62. & PKL & 1 & 1 & - \\
\hline 63. & Skripsi & 1 & 1 & - \\
\hline \multirow{2}{*}{\multicolumn{2}{|c|}{$\begin{array}{c}\text { Jumlah } \\
\text { Persentase }\end{array}$}} & 280 & 22 & 258 \\
\hline & & & $8 \%$ & $92 \%$ \\
\hline
\end{tabular}

Sumber: Data diolah April 2021

Berdasarkan tabel 3, ketersediaan koleksi mata kuliah wajib jurusan Sastra Inggris berdasarkan RPS yaitu tersedia sebanyak 22 judul dari 280 judul yang dibutuhkan dengan persentase $8 \%$ atau sebagian kecil dan koleksi yang tidak tersedia yaitu 92\% atau sebagian besar dengan total 258 judul.

Berdasarkan hasil penelitian, terdapat 5 RPS yang tidak tersedia yaitu mata kuliah Poetry Analysis II, Scientific Reading, Article Writing, Survey of American Literature, dan Seminar Proposal. Selanjutnya untuk mata kuliah wajib jurusan Sastra Inggris yang paling banyak memiliki koleksi bahan ajar akan tetapi sedikit ketersediaannya adalah mata kuliah Literary Criticism dan Popular Culture. 
Palimpsest: Journal of Information and Library Science Vol 12, Issue 2, (2021) page 62-68

Tabel 4.

Ketersediaan koleksi bahan ajar mata kuliah wajib Ilmu Perpustakaan

\begin{tabular}{|c|c|c|c|c|}
\hline No. & Mata Kuliah & $\begin{array}{c}\text { Jumlah } \\
\text { Referensi }\end{array}$ & $\begin{array}{c}\text { Jumlah Koleksi } \\
\text { yang Tersedia }\end{array}$ & $\begin{array}{c}\text { Jumlah Koleksi yang } \\
\text { Tidak Tersedia } \\
\end{array}$ \\
\hline 1. & Pendidikan Pancasila & 8 & 2 & 6 \\
\hline 2. & Bahasa Inggris 1 & 1 & - & 1 \\
\hline 3. & Dasar-Dasar Ilmu Budaya & 3 & 1 & 2 \\
\hline 4. & $\begin{array}{l}\text { Sejarah Kebudayaan } \\
\text { Indonesia }\end{array}$ & 8 & 1 & 7 \\
\hline 5. & $\begin{array}{l}\text { Pengantar Ilmu } \\
\text { Perpustakaan dan Informasi }\end{array}$ & 3 & 2 & 1 \\
\hline 6. & Kearsipan & 8 & 1 & 7 \\
\hline 7. & Psikologi Perpustakaan & 2 & - & 2 \\
\hline 8. & Aksara Arab Melayu & 3 & 1 & 2 \\
\hline 9. & Pendidikan Agama & 3 & - & 3 \\
\hline 10. & $\begin{array}{l}\text { Pendidikan } \\
\text { Kewarganegaraan }\end{array}$ & 6 & 1 & 5 \\
\hline 11. & Bahasa Indonesia & 8 & 1 & 7 \\
\hline 12. & Budaya Melayu & 1 & - & 1 \\
\hline 13. & Dasar-dasar Filsafat & 4 & 1 & 3 \\
\hline 14. & Pengantar Komputer & 3 & - & 3 \\
\hline 15. & Dokumentasi Budaya & 5 & 2 & 3 \\
\hline 16. & Manajemen Perpustakaan & 6 & 4 & 2 \\
\hline 17. & Tajuk Subjek dan Tesaurus & 4 & 1 & 3 \\
\hline 18. & Bahan Rujukan Umum & 2 & 1 & 1 \\
\hline 19. & Ergonomi & 3 & 3 & - \\
\hline 20. & Pelayanan Perpustakaan & 3 & 2 & 1 \\
\hline 21. & $\begin{array}{l}\text { Sistem Jaringan dan } \\
\text { Kerjasama Perpustakaan }\end{array}$ & 1 & - & 1 \\
\hline 22. & Klasifikasi & 4 & 3 & 1 \\
\hline 23. & Katalogisasi & 3 & 2 & 1 \\
\hline 24. & $\begin{array}{l}\text { Pengatalogan Bahan non- } \\
\text { Buku }\end{array}$ & 1 & 1 & - \\
\hline 25. & Pelestarian Bahan Pustaka & 1 & - & 1 \\
\hline 26. & $\begin{array}{l}\text { Aplikasi Database } \\
\text { Perpustakaan }\end{array}$ & 2 & 1 & 1 \\
\hline 27. & Filologi & 7 & 1 & 6 \\
\hline 28. & $\begin{array}{l}\text { Aspek Hukum dalam } \\
\text { Informasi }\end{array}$ & 8 & - & 8 \\
\hline 29. & Perpustakaan Digital & 1 & 1 & - \\
\hline 30. & Kodifikasi Naskah Kuno & 7 & 5 & 2 \\
\hline 31. & Abstrak dan Indeks & 2 & - & 2 \\
\hline 32. & $\begin{array}{l}\text { Penulisan Artikel dan } \\
\text { Resensi Buku }\end{array}$ & 6 & 1 & 5 \\
\hline 33. & $\begin{array}{l}\text { Metode Penelitian } \\
\text { Kuantitatif }\end{array}$ & 2 & - & 2 \\
\hline 34. & Kewirausahaan Pusdokinfo & 5 & 1 & 4 \\
\hline 35. & Metode Penelitian Kualitatif & 1 & - & 1 \\
\hline 36. & $\begin{array}{l}\text { Pemasaran Perpustakaan dan } \\
\text { Informasi }\end{array}$ & 5 & 1 & 4 \\
\hline 37. & Etika Profesi Pustakawan & 5 & 5 & - \\
\hline
\end{tabular}


Palimpsest: Journal of Information and Library Science Vol 12, Issue 2, (2021) page 62-68

\begin{tabular}{cccc}
\hline Jumlah & 145 & 46 & 99 \\
\hline Persentase & & $32 \%$ & $68 \%$ \\
\hline
\end{tabular}

Sumber: Data diolah April 2021

Pada tabel di atas, dapat dilihat bahwa ketersediaan koleksi mata kuliah wajib jurusan Ilmu Perpustakaan berdasarkan RPS yaitu tersedia sebanyak 46 judul atau hampir setengah dengan persentase $32 \%$ dan koleksi yang tidak tersedia sebanyak 99 judul atau lebih dari setengah yaitu $68 \%$.

Berdasarkan hasil penelitian, terdapat 14 RPS yang tidak tersedia yaitu mata kuliah Komunikasi Intruksional Bahasa Inggris 2, Pembinaan Minat Baca, Automasi Perpustakaan, Pengembangan Koleksi, Pengantar Jurnalistik, Temu Kembali Informasi, Statistik Penelitian, Penerbitan Tercetak dan Elektronik, Digitalisasi dan Keamanan Arsip, Pendidikan Pemakai, PKL, Seminar Proposal, serta Skripsi. Selanjutnya untuk mata kuliah wajib jurusan Ilmu Perpustakaan yang paling banyak memiliki koleksi bahan ajar akan tetapi sedikit ketersediaannya adalah mata kuliah Aspek Hukum dalam Informasi.

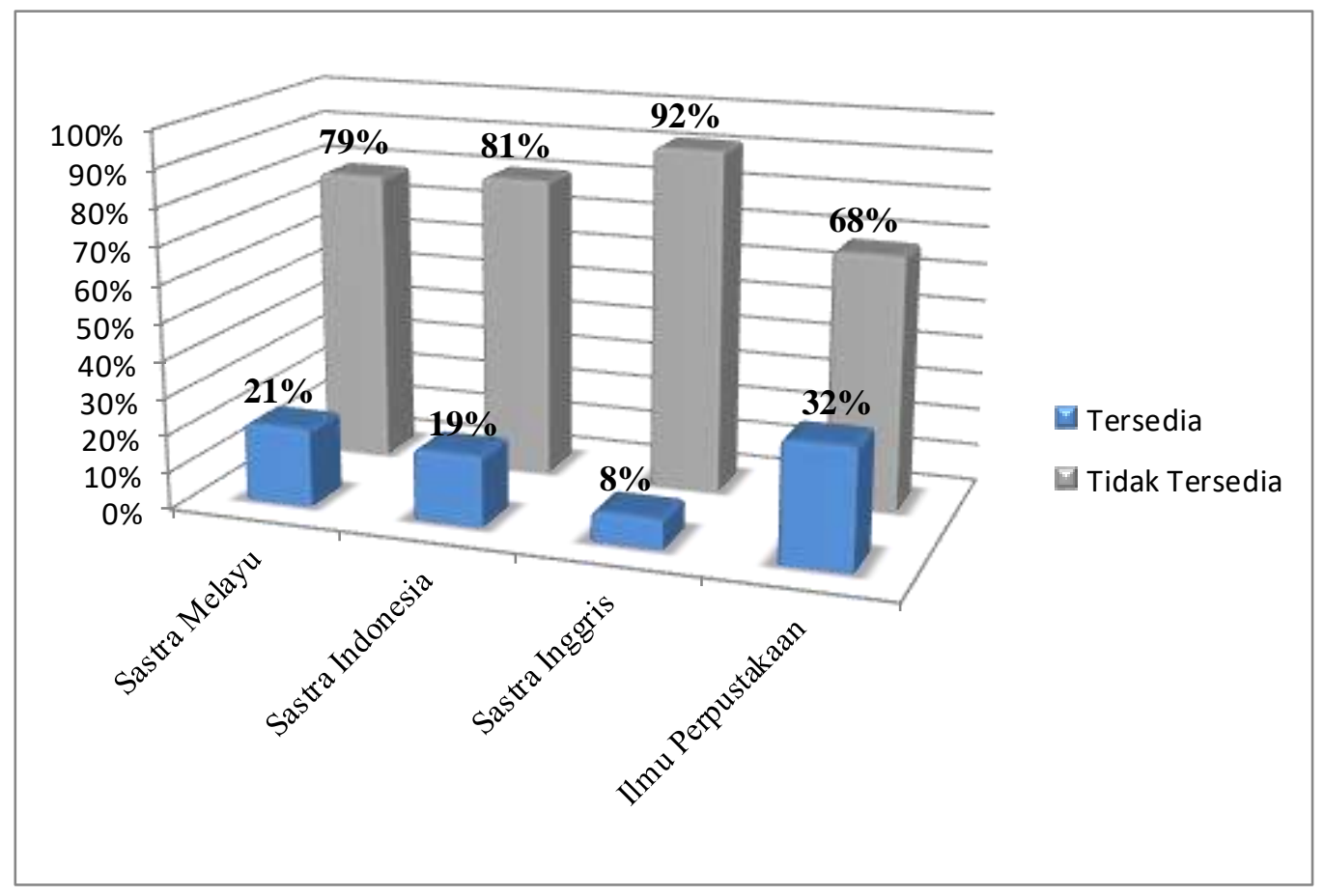

Grafik 1.

Persentase ketersediaan koleksi bahan ajar mata kuliah wajib

Sumber: Data diolah April 2021

Berdasarkan grafik di atas dapat dilihat bahwa tingkat ketersediaan koleksi bahan ajar mata kuliah wajib dari yang tertinggi hingga terendah yaitu terdapat di jurusan Ilmu Perpustakaan dengan jumlah 32\%, jurusan Sastra Melayu 21\%, jurusan Sastra Indonesia 19\%, jurusan Sastra Inggris $8 \%$. Selanjutnya koleksi bahan ajar mata kuliah wajib yang tidak tersedia dari yang tertinggi hingga terendah yaitu terdapat pada jurusan Sastra Inggris 92\%, jurusan Sastra Indonesia 81\%, jurusan Sastra Melayu 79\%, jurusan Ilmu Perpustakaan 68\%. 


\section{Ketersediaan Koleksi Bahan Ajar Mata Kuliah Pilihan}

Mata kuliah pilihan adalah mata kuliah yang boleh dipilih oleh mahasiswa dari daftar yang disediakan perguruan tinggi. Berikut ini merupakan ketersediaan koleksi bahan ajar mata kuliah pilihan program studi Sastra Melayu, Sastra Indonesia, Sastra Inggris, dan Ilmu Perpustakaan.

Tabel 5.

Ketersediaan koleksi bahan ajar mata kuliah pilihan Sastra Melayu

\begin{tabular}{clccc}
\hline No. & Mata Kuliah & $\begin{array}{c}\text { Jumlah } \\
\text { Referensi }\end{array}$ & $\begin{array}{c}\text { Jumlah Koleksi } \\
\text { yang Tersedia }\end{array}$ & $\begin{array}{c}\text { Jumlah Koleksi } \\
\text { yang Tidak } \\
\text { Tersedia }\end{array}$ \\
\hline 1. & Stilistika & 6 & 1 & 5 \\
2. & Sastra Populer & 10 & 2 & 8 \\
3. & Arsitektur Melayu & 2 & - & 2 \\
4. & Etnografi & 6 & 2 & 4 \\
5. & Analisis Wacana & 3 & - & 3 \\
6. & Sosiolinguistik & 3 & 1 & 2 \\
7. & Keterampilan Sosial & 4 & - & 4 \\
8. & Kehumasan & 3 & 1 & 2 \\
\hline \multicolumn{6}{c}{ Jumlah } & $\mathbf{3 7}$ & $\mathbf{7}$ & $\mathbf{3 0}$ \\
\hline \multicolumn{6}{c}{ Persentase } & Sumber: Data diolah Mei 2021
\end{tabular}

Ketersediaan koleksi bahan ajar berdasarkan RPS untuk mata kuliah pilihan jurusan Sastra Melayu yaitu tersedia sebanyak 7 judul dari 37 judul yang dibutuhkan, atau tingkat ketersediaan koleksi sebagian kecil yaitu 19\% dan koleksi yang tidak tersedia sebanyak 30 judul atau sebagian besar yaitu $81 \%$. Selanjutnya untuk mata kuliah pilihan jurusan Sastra Melayu yang paling banyak memiliki koleksi bahan ajar akan tetapi sedikit ketersediaannya adalah mata kuliah Sastra Populer.

Tabel 6.

Ketersediaan koleksi bahan ajar mata kuliah pilihan Sastra Indonesia

\begin{tabular}{ccccc}
\hline No. & Mata Kuliah & $\begin{array}{c}\text { Jumlah } \\
\text { Referensi }\end{array}$ & $\begin{array}{c}\text { Jumlah Koleksi } \\
\text { yang Tersedia }\end{array}$ & $\begin{array}{c}\text { Jumlah Koleksi } \\
\text { yang Tidak } \\
\text { Tersedia }\end{array}$ \\
\hline 1. & Bahasa Sansekerta & 1 & - & 1 \\
2. & Aksara Arab Melayu & 2 & 1 & 1 \\
\hline \multicolumn{7}{c}{ Jumlah } & $\mathbf{3}$ & $\mathbf{1}$ & $\mathbf{2}$ \\
\hline Persentase & & $\mathbf{3 3 \%}$ & $\mathbf{6 7 \%}$ \\
\hline
\end{tabular}

Sumber: Data diolah Mei 2021

Berdasarkan data di atas, koleksi yang tersedia untuk mata kuliah pilihan jurusan Sastra Indonesia yaitu tersedia 1 judul dengan persentase 33\% atau hampir setengahnya dan koleksi yang tidak tersedia lebih dari setengah yaitu $67 \%$ dengan 2 judul koleksi bahan ajar. Dari hasil penelitian, terdapat 3 RPS mata kuliah pilihan jurusan Sastra Indonesia yang tidak tersedia yaitu mata kuliah Kepariwisataan, Penyiaran, dan Periklanan. 
Palimpsest: Journal of Information and Library Science Vol 12, Issue 2, (2021) page 64-68

Tabel 7.

Ketersediaan koleksi bahan ajar mata kuliah pilihan Sastra Inggris

\begin{tabular}{ccccc}
\hline No. & Mata Kuliah & $\begin{array}{c}\text { Jumlah } \\
\text { Referensi }\end{array}$ & $\begin{array}{c}\text { Jumlah Koleksi } \\
\text { yang Tersedia }\end{array}$ & $\begin{array}{c}\text { Jumlah Koleksi } \\
\text { yang Tidak } \\
\text { Tersedia }\end{array}$ \\
\hline 1. & Language and media & 3 & - & 3 \\
2. & Theatrical Performance & 7 & 1 & 6 \\
\hline \multicolumn{7}{c}{ Jumlah } & $\mathbf{1 0}$ & $\mathbf{1}$ & $\mathbf{9}$ \\
\hline Persentase & & $\mathbf{1 0 \%}$ & $\mathbf{9 0 \%}$ \\
\hline
\end{tabular}

Menurut tabel di atas, ketersediaan koleksi bahan ajar mata kuliah pilihan Jurusan Sastra Inggris yaitu tersedia 1 judul dengan persentase $10 \%$ atau sebagian kecil dan koleksi yang tidak tersedia yaitu $90 \%$ atau sebagian besar dengan total sebanyak 9 judul. Selanjutnya untuk mata kuliah pilihan jurusan Sastra Inggris yang paling banyak memiliki koleksi bahan ajar akan tetapi sedikit ketersediaannya adalah mata kuliah Theatrical Performance.

Tabel 8.

Ketersediaan koleksi bahan ajar mata kuliah pilihan Ilmu Perpustakaan

\begin{tabular}{llccc}
\hline No. & \multicolumn{1}{c}{ Mata Kuliah } & $\begin{array}{c}\text { Jumlah } \\
\text { Referensi }\end{array}$ & $\begin{array}{c}\text { Jumlah Koleksi } \\
\text { yang Tersedia }\end{array}$ & $\begin{array}{c}\text { Jumlah Koleksi } \\
\text { yang Tidak } \\
\text { Tersedia }\end{array}$ \\
\hline $\begin{array}{l}\text { 1. } \\
\text { Aplikasi Open Source }\end{array}$ & 2 & 1 & 1 \\
3. & $\begin{array}{l}\text { Pesain Web } \\
\text { Perpustakaan Sekolah dan }\end{array}$ & 1 & 1 & - \\
\hline & 2 & 2 & - \\
\hline & Jumlah & $\mathbf{5}$ & $\mathbf{4}$ & $\mathbf{1}$ \\
\hline
\end{tabular}

Sumber: Data diolah Mei 2021

Dapat dilihat dari tabel di atas bahwa ketersediaan koleksi mata kuliah pilihan jurusan Ilmu Perpustakaan berdasarkan RPS yaitu tersedia 4 judul atau tingkat ketersediaannya lebih dari setengah yaitu $80 \%$ dan koleksi yang tidak tersedia sebanyak 1 judul dengan persentase $20 \%$ atau sebagian kecil.

Berdasarkan hasil penelitian, terdapat 1 RPS mata kuliah pilihan jurusan Ilmu Perpustakaan yang tidak tersedia yaitu mata kuliah Lembaga Pusdokinfo.

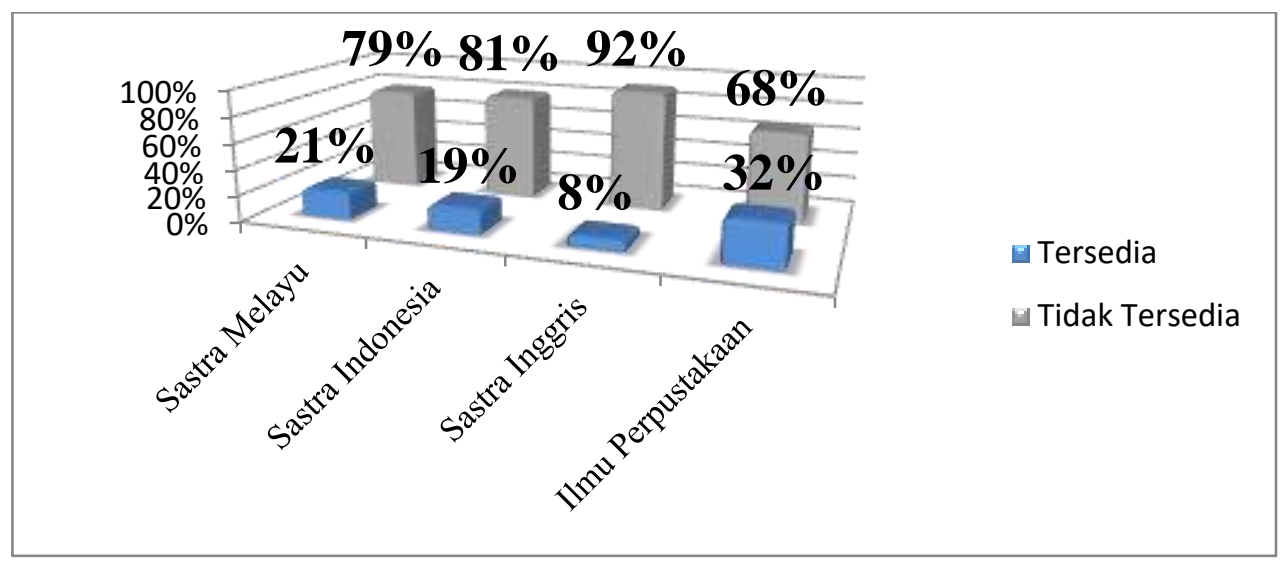


Palimpsest: Journal of Information and Library Science Vol 12, Issue 2, (2021) page 65-68

Grafik 2.

Persentase ketersediaan koleksi bahan ajar mata kuliah pilihan

Sumber: Data diolah April 2021

Dapat dilihat dari grafik di atas bahwa tingkat ketersediaan koleksi bahan ajar mata kuliah pilihan dari yang tertinggi hingga terendah yaitu terdapat pada jurusan Ilmu Perpustakaan dengan jumlah 80\%, kemudian jurusan Sastra Indonesia 33\%, selanjutnya jurusan Sastra Melayu 19\%, dan Jurusan sastra Inggris 10\%. Sedangkan koleksi bahan ajar mata kuliah pilihan yang tidak tersedia dari yang tertinggi hingga terendah yaitu terdapat pada jurusan Sastra Inggris dengan jumlah 90\%, kemudian jurusan Sastra Melayu 81\%, selanjutnya jurusan Sastra Indonesia 67\% dan jurusan Ilmu Perpustakaan $20 \%$.

Tabel 9.

Data ketersediaan seluruh koleksi bahan ajar mata kuliah wajib

\begin{tabular}{ccccccc}
\hline No. & \multicolumn{1}{c}{ Prodi } & $\begin{array}{c}\text { Jumlah } \\
\text { Referensi }\end{array}$ & $\begin{array}{c}\text { Jumlah Koleksi } \\
\text { yang Tersedia }\end{array}$ & \% & $\begin{array}{c}\text { Jumlah Koleksi yang } \\
\text { Tidak Tersedia }\end{array}$ & \% \\
\hline 1. & Sastra Melayu & 262 & 56 & $21 \%$ & 206 & $79 \%$ \\
2. & Sastra Indonesia & 115 & 22 & $19 \%$ & 93 & $81 \%$ \\
3. & $\begin{array}{l}\text { Sastra } \\
\text { Inggris }\end{array}$ & 280 & 22 & $8 \%$ & 258 & $92 \%$ \\
4. & $\begin{array}{l}\text { Ilmu } \\
\text { Perpustakaan }\end{array}$ & 145 & 46 & $32 \%$ & 99 & $68 \%$ \\
\hline & Jumlah & $\mathbf{8 0 2}$ & $\mathbf{1 4 6}$ & $\mathbf{1 8 \%}$ & $\mathbf{6 5 6}$ & $\mathbf{8 2 \%}$ \\
\hline
\end{tabular}

Sumber: Data diolah Mei 2021

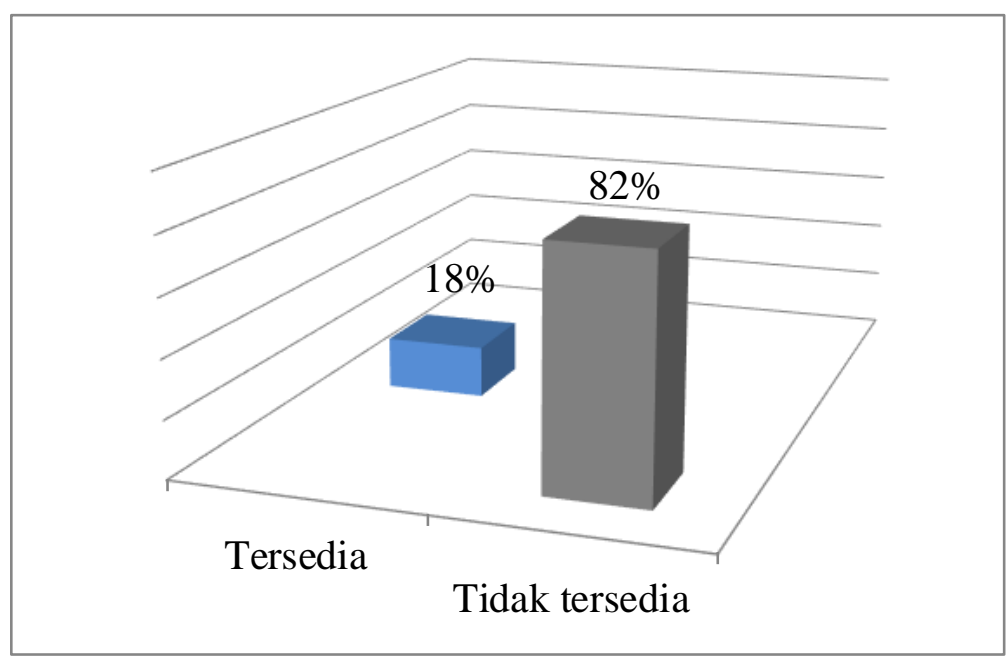

Grafik 3.

Persentase ketersediaan seluruh koleksi bahan ajar mata kuliah wajib

Sumber: Data diolah April 2021

Berdasarkan tabel dan grafik di atas, dapat dilihat bahwa ketersediaan koleksi mata kuliah wajib dari keempat jurusan yang ada di Fakultas Ilmu Budaya dari total koleksi yang dibutuhkan sebagian kecil yaitu $18 \%$ atau 146 judul koleksi yang tersedia di Perpustakaan Fakultas Ilmu Budaya. Dan sebagian besar yaitu $82 \%$ atau 656 judul koleksi yang tidak tersedia di Perpustakaan Fakultas Ilmu Budaya. 
Berdasarkan tabel di atas juga dapat diketahui bahwa ketersediaan koleksi mata kuliah wajib yang paling banyak tersedia di Perpustakaan Fakultas Ilmu budaya Universitas Lancang Kuning adalah koleksi bahan rujukan jurusan Ilmu Perpustakaan. Koleksi yang paling sedikit tersedia adalah koleksi bahan rujukan jurusan Sastra Inggris.

Tabel 10.

Data ketersediaan seluruh koleksi bahan ajar mata kuliah pilihan

\begin{tabular}{llccccc}
\hline No. & \multicolumn{1}{c}{ Prodi } & $\begin{array}{c}\text { Jumlah } \\
\text { Referensi }\end{array}$ & $\begin{array}{c}\text { Jumlah Koleksi } \\
\text { yang Tersedia }\end{array}$ & \% & $\begin{array}{c}\text { Jumlah Koleksi yang } \\
\text { Tidak Tersedia }\end{array}$ & \% \\
\hline 1. & Sastra Melayu & 37 & 7 & $19 \%$ & 30 & $81 \%$ \\
2. & Sastra Indonesia & 3 & 1 & $33 \%$ & 2 & $67 \%$ \\
3. & $\begin{array}{l}\text { Sastra } \\
\text { Inggris }\end{array}$ & 10 & 1 & $10 \%$ & 9 & $90 \%$ \\
4. & $\begin{array}{l}\text { Ilmu } \\
\text { Perpustakaan }\end{array}$ & 5 & 4 & $80 \%$ & 1 & $20 \%$ \\
\hline & Jumlah & $\mathbf{5 5}$ & $\mathbf{1 3}$ & $\mathbf{2 4 \%}$ & $\mathbf{4 2}$ & $\mathbf{7 6 \%}$ \\
\hline
\end{tabular}

Sumber: Data diolah Mei 2021

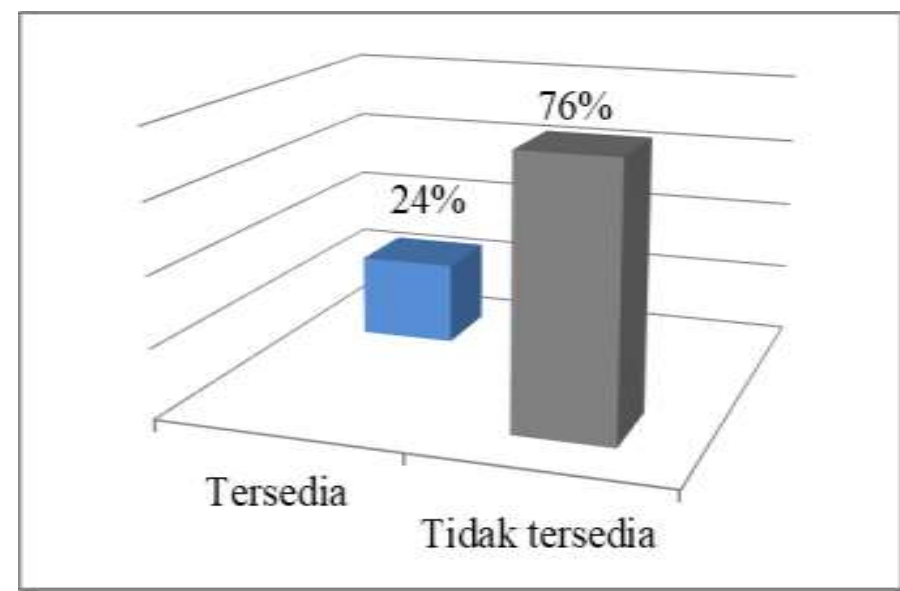

Grafik 4.

Persentase ketersediaan seluruh koleksi bahan ajar mata kuliah pilihan

Sumber: Data diolah April 2021

Dapat dilihat dari tabel dan grafik di atas, dapat dilihat bahwa ketersediaan koleksi mata kuliah pilihan dari keempat jurusan yang ada di Fakultas Ilmu Budaya dari total koleksi yang dibutuhkan hampir setengah yaitu $24 \%$ atau 13 judul koleksi yang tersedia di Perpustakaan Fakultas Ilmu Budaya. Lebih dari setengah yaitu $76 \%$ atau 42 judul koleksi yang tidak tersedia di Perpustakaan Fakultas Ilmu Budaya.

Dapat juga diketahui bahwa ketersediaan koleksi mata kuliah pilihan yang paling banyak tersedia di Perpustakaan Fakultas Ilmu budaya Universitas Lancang Kuning adalah koleksi bahan rujukan jurusan Ilmu Perpustakaan. Koleksi yang paling sedikit tersedia adalah koleksi bahan rujukan jurusan Sastra Inggris

\section{Kesimpulan}

Dari hasil dan pembahasan dapat disimpulkan bahwa ketersediaan koleksi mata kuliah wajib dari keempat jurusan yang ada di Fakultas Ilmu Budaya dari total koleksi yang dibutuhkan sebagian kecil yaitu 18\% atau 146 judul koleksi yang tersedia di Perpustakaan Fakultas Ilmu 
Budaya. Dan sebagian besar yaitu $82 \%$ atau 656 judul koleksi yang tidak tersedia di Perpustakaan Fakultas Ilmu Budaya. Kemudian ketersediaan koleksi mata kuliah pilihan dari keempat jurusan yang ada di Fakultas Ilmu Budaya dari total koleksi yang dibutuhkan hampir setengah yaitu 24\% atau 13 judul koleksi yang tersedia di Perpustakaan Fakultas Ilmu Budaya. Kemudian, lebih dari setengah yaitu $76 \%$ atau 42 judul koleksi yang tidak tersedia di Perpustakaan Fakultas Ilmu Budaya.

Dari simpulan yang telah dipaparkan maka penulis akan memberikan saran kepada Perpustakaan Fakultas Ilmu Budaya, hendaknya pemangku kebijakan Perpustakaan Fakultas Ilmu Budaya Universitas Lancang Kuning dapat mengupayakan pengadaan koleksi bahan ajar berdasarkan Rencana Pembelajaran Semester (RPS) untuk memenuhi kebutuhan informasi dosen dalam memberikan materi-materi perkuliahan dan untuk memenuhi kebutuhan informasi mahasiswa dalam pembelajaran.

\section{Daftar Pustaka}

Anggraini, L., \& Bakhtaruddin, N. (2013). Evaluasi Ketersediaan Koleksi Dengan Menggunakan Analisis Sitiran Terhadap Tesis Mahasiswa Pascasarjana Program Studi Ilmu Biomedik Tahun 2012 Di Perpustakaan Fakultas Kedokteran Universitas Andalas. Jurnal Ilmu Informasi Perpustakaan Dan Kearsipan, 2(1): 159-168.

Azzahra, E. (2016). Analisis Pemanfaatan Koleksi Perpustakaan Oleh Mahasiswa Fakultas Syari' Ah Dan Hukum Uin Ar-Raniry Banda Aceh. Banda Aceh: Universitas Islam Negeri Ar-Raniry.

Junaeti. (2019). Ketersediaan Koleksi Berdasarkan Silabus Dan Standar Ban-Pt: Analisis Koleksi Perpustakaan Iain Pekalongan Untuk Jurusan Pendidikan Agama Islam Ftik Iain Pekalongan. Pustakaloka: Jurnal Kajian Informasi Dan Perpustakaan, 11(1): 54-79.

Kepala Perpustakaan Nasional Ri. Peraturan Kepala Perpustakaan Nasional Republik Indonesia Nomor 13 Tahun 2017 Tentang Standar Nasional Perpustakaan Perguruan Tinggi. Kepala Perpustakaan Nasional Ri (2017).

Maryam, S. (2015). Evaluasi Koleksi Perpustakaan Uin Syarif Hidayatullah Jakarta Berdasar Analisis Sitasi Penelitian Dosen. Jakarta: Puslitpen.

Maslahah, K., \& Hasanah Rahmawati, N. (2018). Evaluasi Koleksi Berdasarkan Silabus Program Studi Bimbingan Dan Konseling Islam Di Upt Pusat. Jurnal Ilmu Informasi, Perpustakaan Dan Kearsipan, 20(2): 77-86.

Ns, Sutarno. (2006). Manajemen Perpustakaan: Suatu Pendekatan Praktik. Jakarta: Sagung Seto.

Nurdin, S. (2018). Pengembangan Kurikulum Dan Rencana Pembelajaran Semester ( RPS ) Berbasis KKNI Di Perguruan Tinggi. Jurnal Pendidikan Islam 1(2): 140-147.

Pedoman Penyelenggaraan Perpustakaan Perguruan Tinggi. (2015). Jakarta: Perpustakaan Nasional Republik Indonesia.

Peraturan Menteri Riset, Teknologi, Dan Pendidikan Tinggi Republik Indonesia Nomor 44 Tahun 2015 Tentang Standar Nasional Pendidikan Tinggi. (2015).

Perpustakaan Perguruan Tinggi: Buku Pedoman. (2004). Departemen Pendidikan Nasional Ri Direktorat Jendral Pendidikan Tinggi.

Petrus Sitepu, B., \& Lestari, I. (2018). Pelaksanaan Rencana Pembelajaran Semester Dalam Proses Pembelajaran Di Perguruan Tinggi. Perspektif Ilmu Pendidikan, 32(1), 43-51.

Rifauddin, M., \& A. Nurma, H. (2018). Evaluasi Koleksi Bahan Pustaka Di Perpustakaan. Adabiya, 20(2): 35-45.

Romadhoni, S. (2016). Evaluasi Ketersediaan Koleksi Berbasis Silabus Program Studi Pendidikan Matematika Di Perpustakaan Universitas Muhammadiyah Purworejo. 
Palimpsest: Journal of Information and Library Science Vol 12, Issue 2, (2021) page 68-68

Yogyakarta: Universitas Islam Negeri Sunan Kalijaga.

Sudiar, N., H, R., \& Mafar, F. (2018). Evaluasi Koleksi Referensi Di Perpustakaan Man 1 Pekanbaru. Jurnal Ilmu Budaya, 15(2): 56-64.

Sugiyono. (2017). Metode Penelitian Bisnis : Pendekatan Kuantitatif, Kualitatif, Kombinasi, Dan $R \& D$. Bandung: Alfabeta.

Syukrinur. (2017). Evaluasi Koleksi : Antara Ketersediaan Dan Keterpakaian Koleksi. Libria, 9(1): 93-102.

Undang-Undang Perpustakaan Nomor 43 Tahun 2007. (2007). Indonesia.

Winoto, Y., \& Kusumawati, D. (2019). Penggunaan Metode Collection-Centered Dalam Kegiatan Evaluasi Koleksi Di Perpustakaan Institut Agama Islam Negeri ( Iain ) Syekh Nurjati Cirebon. Al-Kuttab: Jurnal Kajian Perpustakaan, Informasi Dan Kearsipan, 1(1): 13-22. 